\title{
Effect of inhibiting Beclin-1 expression on autophagy, proliferation and apoptosis in colorectal cancer
}

\author{
LIN LIU*, WEI-MIN ZHAO*, XIN-HUI YANG, ZHEN-QIANG SUN, \\ HUI-ZHEN JIN, CHENG LEI, BO JIN and HAI-JIANG WANG \\ Department of Abdominal Surgery, Cancer Hospital Affiliated to Xinjiang Medical University, \\ Urumqi, Xinjiang 830011, P.R. China
}

Received September 21, 2015; Accepted March 31, 2017

DOI: $10.3892 / 01.2017 .6687$

\begin{abstract}
The present study aimed to investigate the molecular mechanisms and effect of Beclin-1 on autophagy, proliferation and apoptosis in the colorectal cancer (CRC) HCT116 and SW620 cells. Beclin-1 was silenced by RNA interference (RNAi) in HTC116 and SW620 cells. Reverse transcription-polymerase chain reaction and western blot were used to measure the expression of Beclin-1. The percentage of apoptotic cells was analyzed by cell counting kit-8 (CCK-8) and flow cytometry (FCM). Cell cycle and cell proliferation were analyzed by FCM and the MTT assay. The present study created 3 groups in the two cell lines, consisting of the targeting siRNA (TS) group, in which Beclin-1 was partially silenced, non-specific siRNA (NS) group and control group (CG; without transfection). By siRNA transfection, the mRNA and protein level of Beclin-1 in the TS group were significantly inhibited compared with the NS group and CG $(\mathrm{P}<0.05)$. After $0,24,48$ and $72 \mathrm{~h}$, the survival rate of the cells in the TS group was significantly decreased compared with the survival rate of the cells in the NS group and CG, as detected by CCK- 8 methods $(\mathrm{P}<0.05)$. FCM and MTT results showed the apoptotic rate of the cells in the TS group was significantly decreased compared with the rate in the NS group and CG $(\mathrm{P}<0.05)$, and the proliferation of the cells in the NS group was evidently increased compared with the CG. In conclusion, Beclin-1 played an important role in regulating autophagy, proliferation and apoptosis in HCT116 and SW620 cells. The inhibition of Beclin-1 by RNAi suppressed the autophagic activity and proliferation, but promoted apoptosis in CRC cells. Beclin-1 was the new target of gene therapy for CRC.
\end{abstract}

Correspondence to: Dr Hai-Jiang Wang, Department of Abdominal Surgery, Cancer Hospital Affiliated to Xinjiang Medical University, 789 Suzhou East Street, Urumqi, Xinjiang 830011, P.R. China E-mail: wanghaijang_1@163.com

*Contributed equally

Key words: colorectal cancer, HCT116 cells, Beclin-1, small interfering RNA, autophagy, proliferation, apoptosis

\section{Introduction}

Autophagy, as a major catabolic pathway in which the cell degrades macromolecules and damaged organelles, was involved in the process of cell proliferation, differentiation, survival and homeostasis (1-2). The characteristics of autophagy were the autophagosome with double layer membrane wrapping the long lived proteins and organelles, was the process that during starvation, many organisms retrieve nutrients via degradation of their own intracellular components (3). Autophagy is common in numerous eukaryotic cells and relative to cell death (4). Previous studies have shown that autophagy appeared in numerous tumors, including colorectal cancer (CRC), esophageal carcinoma, breast cancer, lung cancer and pancreatic cancer. However, the initiation mechanism of autophagy in CRC was remained unclear. Yang et al (5) found that autophagy not only improves the adaptability and promotes the proliferation of tumor cells, but also induces cell death. At present, there are few studies investigating the association between autophagy and the proliferation and apoptosis of CRC. Numerous factors were active in the generating process of autophagy, with the complicated regulation mechanism $(3,5)$. Beclin-1, as the first identified mammalian autophagic gene, was an important regulator and may drive autophagosome formation by binding to VPS34 (6). In the present study, Beclin-1 was silenced by RNA interference (RNAi) and the mRNA and protein expression was detected to investigate the effect of Beclin-1 on proliferation and apoptosis in CRC cells, providing additional evidence to support the treatment of CRC with gene therapy.

\section{Materials and methods}

Cell lines and cell culture. The human colorectal cancer HCT116 and SW620 cell lines were obtained from the Institute of Biochemistry and Cell Biology (Shanghai, China). HCT116 and SW620 cells were cultured with high-glucose Dulbecco's modified Eagle's medium (Gibco; Thermo Fisher Scientific, Inc., Waltham, MA, USA) containing $10 \%$ fetal bovine serum (Gibco; Thermo Fisher Scientific, Inc.) and penicillin-streptomycin $(10,000 \mathrm{U} / \mathrm{ml}$; 1:100; Gibco; Thermo Fisher Scientific, Inc.) in a Heracell ${ }^{\mathrm{TM}}$ VIOS $160 \mathrm{i} \mathrm{CO}_{2}$ incubator (Thermo Fisher Scientific, Inc.), and were maintained in a $5 \% \mathrm{CO}_{2}$ atmosphere 
at $37^{\circ} \mathrm{C}$. The cells were replaced with new medium every 2 or 3 days and passaged when the confluence reached $90 \%$ using 0.25\% Trypsin-ENTA (Gibco; Thermo Fisher Scientific, Inc.).

Small interfering (si)RNA transfection. The siRNA targeting Beclin-1 was constructed by Shanghai GenePharma Co., Ltd. (Shanghai, China). The siRNA sequences were as follows: Beclin-1 sense, 5'-CAC CGG ACA ACA AGT TTG ACC ATG CTT CAA GAG AGC ATG GTC AAA CTT GTT GTC CTT TTTTG-3' and antisense, 5'-GAT CCA AAA AAG GAC AAC AAG TTT GAC CAT GCT CTC TTG AAG CAT GGT CAA ACT TGT TGTCC-3'. The sequences were then cloned into the plasmid of pSilencer 3.1 H1-neo (Addgene, USA) to generate the plasmid pSilencer-Beclin-1. HCT116 cells were seeded onto $6-\mathrm{cm}$ petri dishes $\left(5 \times 10^{5}\right.$ cells/well $)$ and stably transfected at $80 \%$ confluence with siRNA. All the dishes were divided into 3 groups, consisting of the targeting siRNA (TS) and nonspecific siRNA (NS) groups and the control group (CG), with 3 dishes for each group. The cells in the TS group were transfected with siRNA targeting Beclin-1, while the cells in the NS group were transfected with non-targeting siRNA, using Lipofectamine ${ }^{\circledR} 3000$ Transfection Reagent (Invitrogen; Thermo Fisher Scientific, Inc.). After $72 \mathrm{~h}$, the cells were replaced with new medium containing $400 \mu \mathrm{g} / \mathrm{ml}$ G418 (Gibco; Thermo Fisher Scientific, Inc.). The surviving cells were grown and selected with medium containing $400 \mu \mathrm{g} / \mathrm{ml}$ G418.

RNA extraction and reverse transcription-polymerase chain reaction $(R T-P C R)$. Two weeks subsequent to transfection and selection with G418, the total cellular RNA was extracted with TRIzol ${ }^{\circledR}$ reagent (Invitrogen; Thermo Fisher Scientific, Inc.). The extracted RNA was analyzed with ethidium bromide-stained $1 \%$ agarose gel by electrophoresis. Beclin-1 mRNA was tested by RT-PCR using SYBR Premix Ex Taq (Takara Biotechnology Co., Ltd., Dalian, China). The primer sequences were constructed by Thermo Fisher Scientific, Inc., as follows: Beclin-1 sense, 5'-GGATGGATGTGGAGA AAGGCAAG-3' and antisense, 5'-TGAGGACACCCAAGC AAGACC-3'; $\beta$-actin sense, 5'-ATCGTGCGTGACATTAAG GAGAAG-3' and antisense, 5'-AGGAAGGAAGGCTGG AAGAGTG-3'. The PCR conditions are shown in Table I, and the amplification conditions are shown in Table II. The fold-change in gene expression was calculated using the $2^{-\Delta \Delta \mathrm{Ca}}$ method (7).

Western blot analysis. All cells were washed twice with PBS, centrifuged at $1,000 \mathrm{x}$ g for $5 \mathrm{~min}$, and resuspended in radioimmunoprecipitation assay lysis and extraction buffer (Thermo Fisher Scientific, Inc.), containing $1 \mathrm{mM}$ phenylmethylsulfonyl fluoride protease inhibitor (Thermo Fisher Scientific, Inc.) on ice for $30 \mathrm{~min}$ to completely lyse. Loading buffer $(5 \mathrm{X})$ was added and boiled at $100^{\circ} \mathrm{C}$ for $10 \mathrm{~min}$. The This was then centrifuged at $12,000 \mathrm{x}$ g for $10 \mathrm{~min}$ and the supernatant was collected. The total protein concentration was detected using the bicinchoninic acid method (Beyotime Institute of Biotechnology, Haimen, China).

A total of, $10 \mu \mathrm{g}$ protein from each sample was separated by SDS-PAGE, with a 5\% stacking gel and $10 \%$ separating gel, and transferred to polyvinylidene fluoride membranes (Merck
Table I. Reverse transcription-PCR system (20- $\mu$ l reaction system).

\begin{tabular}{|c|c|c|c|}
\hline \multicolumn{2}{|l|}{ Composition } & \multicolumn{2}{|r|}{ Volume, $\mu 1$} \\
\hline Ultrapure water & & & 7 \\
\hline 2X PCR Mix & & & 10 \\
\hline \multicolumn{4}{|l|}{ Primer } \\
\hline Forward & & & 1 \\
\hline Reverse & & & 1 \\
\hline Template cDNA & & & 1 \\
\hline Total volume & & & 20 \\
\hline \multicolumn{4}{|c|}{ PCR, polymerase chain reaction. } \\
\hline \multicolumn{4}{|c|}{ Table II. Polymerase chain reaction amplification conditions. } \\
\hline Step & $\begin{array}{c}\text { Temperature, } \\
{ }^{\circ} \mathrm{C}\end{array}$ & Time & $\begin{array}{c}\text { Cycle } \\
\text { number }\end{array}$ \\
\hline Predegeneration & 95 & $5 \mathrm{~min}$ & \\
\hline Degeneration & 95 & $30 \mathrm{sec}$ & 40 \\
\hline Annealing & $58-61$ & $30 \mathrm{sec}$ & \\
\hline Extension & 72 & $1 \mathrm{~min}$ & \\
\hline Extension terminal & 72 & $30 \mathrm{~min}$ & 1 cycle \\
\hline Storage & 4 & Indefinitely & \\
\hline
\end{tabular}

KGaA, Darmstadt, Germany). The membranes were then blocked with Tris-buffered saline containing $0.05 \%$ Tween-20 (TBST) and 5\% non-fat milk for $1 \mathrm{~h}$ at room temperature. Rabbit polyclonal anti-Beclin-1 (dilution, 1:200; catalog no., sc-11427; Santa Cruz Biotechnology, Inc., Dallas, TX, USA) and mouse monoclonal anti- $\beta$-actin (dilution, 1:200; catalog no., sc-47778; Santa Cruz Biotechnology, Inc.) antibodies were added to incubate at $4^{\circ} \mathrm{C}$ overnight. Following washing with TBST, the membranes were incubated with goat anti-rabbit (dilution, 1:3,000; catalog no., 111-035-003; Jackson ImmunoResearch, Inc., West Grove, PA, USA) and peroxidase-conjugated goat anti-mouse (dilution, 1:3,000; catalog no., 115-035-003; Jackson ImmunoResearch, Inc.) secondary antibodies for $1 \mathrm{~h}$ at room temperature. Subsequent to washing with TBST, the membranes were developed by electrochemiluminescence using the Enhanced Chemiluminescence system (Merck KGaA, Darmstadt, Germany). Image J software (version 2.1; National Institutes of Health, Bethesda, MD, USA) was used analyze the results and calculate the expression of Beclin-1 as a ratio of Beclin-1 to $\beta$-actin. Following this, the reduction in protein expression was presented as the ratio of TS or NS to CG (100\%).

Apoptosis analysis by Cell Counting Kit (CCK)-8 detection. One day prior to the transfection, HCT116 and SW620 cells were seeded onto a 96-well plate, with $8 \times 10^{3}$ cells and $100 \mu 1$ medium without penicillin-streptomycin each well, in at least 3 wells per group. CCK-8 detection was performed at 0,24 , 48 and $72 \mathrm{~h}$ following transfection. Prior to detection, $10 \mu \mathrm{l}$ CCK-8 liquid was added to each well and incubated at $37^{\circ} \mathrm{C}$ 
in a $5 \% \mathrm{CO}_{2}$ atmosphere for $1 \mathrm{~h}$. The optical density (OD) of each well was detected at $450 \mathrm{~nm}$ using a Synergy HTX multi-mode microplate reader, (BioTek China, Beijing, China) and the average OD was calculated. The relative survival rate was calculated as follows: Relative survival rate $(\%)=(\mathrm{OD}$ of TS group)/(OD of CG)x100.

Cell apoptosis and cell cycle analysis by flow cytometry (FCM). The apoptosis incidence in HCT116 and SW620 cells was detected using fluorescein isothiocyanate (FITC) Annexin V Apoptosis Detection kit (Pharmingen ${ }^{\mathrm{TM}}$; BD Biosciences, Franklin Lakes, NJ, USA), according to the specification. One day prior to transfection, the cells were seeded onto the 6 -well plate, with $7.5 \times 10^{5}$ cells and $2 \mathrm{ml}$ medium without penicillin-streptomycin in each well, and at least 3 wells per group. The cells were trypsinized using Trypsin-ENTA and centrifuged at $3,000 \mathrm{x} \mathrm{g}$ for $5 \mathrm{~min}$ at $25^{\circ} \mathrm{C}, 48 \mathrm{~h}$ after transfection. The cells were collected and $500 \mu \mathrm{l}$ binding buffer was added to resuspend the cells, and then $5 \mu \mathrm{l}$ each of Annexin V-FITC and propidium iodide (PI) were added. The cells were incubated at room temperature in the dark for $15 \mathrm{~min}$. The percentage of cells with different DNA content was calculated. The apoptotic cells were quantified and represented as a percentage of the total, including those stained positive by Annexin V-FITC and negative by PI.

For cell cycle analysis, the cells were trypsinized and centrifuged at $3,000 \mathrm{xg}$ for $5 \mathrm{~min}$ at $25^{\circ} \mathrm{C}$, then washed with $\mathrm{PBS}$ and fixed with $70 \%$ precooled ethanol at $4^{\circ} \mathrm{C}$ overnight. The cells were washed with PBS and stained with PI ( $5 \mathrm{mg} / \mathrm{ml})$ containing $100 \mu \mathrm{l}$ RNAse A $(180 \mu \mathrm{g} / \mathrm{ml}$; Thermo Fisher Scientific, Inc.). The cells were then incubated at room temperature in the dark for $30 \mathrm{~min}$. PI was excited at $488 \mathrm{~nm}$ and fluorescence was analyzed at $630 \mathrm{~nm}$ using a spectrophotometer. Analytical DNA FCM (CytoFLEX; Beckman Coulter, Inc., Brea, CA, USA) was used for cell-cycle phase-distribution analysis.

Proliferation analysis by MTT assay. HCT116 and SW620 cells in each group were seeded onto a 96-well plate, with $1 \times 10^{4}$ cells per well. The cells were treated with $10 \mu 1 \mathrm{MTT}$ reagent at 24, 48 and $72 \mathrm{~h}$ using the Vybrant ${ }^{\circledR}$ MTT Cell Proliferation Assay kit (Thermo Fisher Scientific, Inc.), according to the manufacturer's instructions. The absorbent value was measured at $450 \mathrm{~nm}$ with enzyme immunoassay analyzer (Bio-Rad Laboratories, Inc., Hercules, CA, USA) and the proliferation activity was calculated.

Statistical analysis. The data were analyzed by SPSS 13.0 (SPSS, Inc., Chicago, IL, USA) and presented as the mean \pm standard deviation. Three repeats were performed for each assay. One-way analysis of variance was used to analyze the differences between groups. A t-test was conducted for comparison between groups. $\mathrm{P}<0.05$ was considered to indicate a statistically significant difference.

\section{Results}

Silencing on Beclin-1 expression. Using RNAi, Beclin-1 expression was partially silenced in HCT116 and SW620 cells. The mRNA level was evaluated by RT-PCR and the protein level was evaluated by western blot analysis.

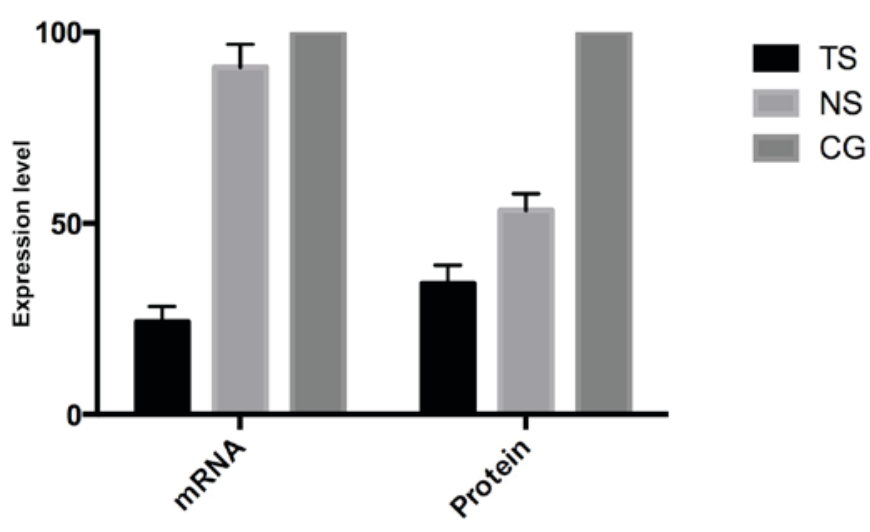

Figure 1. Beclin-1 mRNA expression in TS and NS groups, and CG of HCT116 cells. siRNA, small interfering RNA; TS, targeting siRNA; NS, nonspecific siRNA; CG, control group.

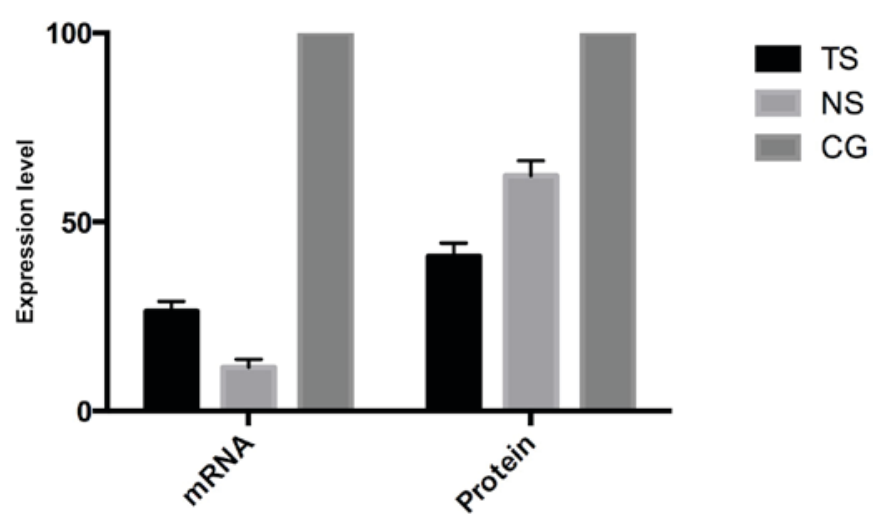

Figure 2. Beclin-1 mRNA expression in TS and NS groups, and CG of SW620 cells. siRNA, small interfering RNA; TS, targeting siRNA; NS, nonspecific siRNA; CG, control group.

Subsequent to transfecting HCT116 cells, the Beclin-1 mRNA in TS group was evidently decreased by $85.7 \%$ $(\mathrm{P}<0.05)$ compared with the $\mathrm{CG}$, while Beclin-1 expression in the NS group was decreased by $9.2 \%$ (Fig. 1). At the protein level, the Beclin-1 expression in TS was decreased by $65.7 \%$ compared with the $\mathrm{CG}$, while the expression in the NS group was decreased by $46.6 \%$, consistent with the mRNA level.

Subsequent to transfecting SW620 cells, Beclin-1 mRNA expression in the TS group was evidently decreased by $73.6 \%$ $(\mathrm{P}<0.05)$ compared with the $\mathrm{CG}$, while in the NS group Beclin-1 expression was decreased by $8.5 \%$ (Fig. 2). On the protein level, Beclin-1 expression in the TS group was decreased by $59.1 \%$ compared with the CG, while in the NS group Beclin-1 expression was decreased by $37.8 \%$, which is consistent with the mRNA level.

Apoptosis analysis by CCK-8 detection. HCT116 and SW620 cells were transfected and the apoptotic percentage was detected by CCK- 8 after $0,24,48$ and $72 \mathrm{~h}$.

Compared with the CG of HCT116 cells, the relative survival rates of the TS group at $0,24,48$ and $72 \mathrm{~h}$ subsequent to transfection were $1.34 \pm 0.038,0.79 \pm 0.020,0.65 \pm 0.054$ and $0.50 \pm 0.011$, respectively, and in the NS group these were $1.29 \pm 0.046,1.08 \pm 0.033,1.02 \pm 0.014$ and $0.98 \pm 0.044$ (Fig. 3). 


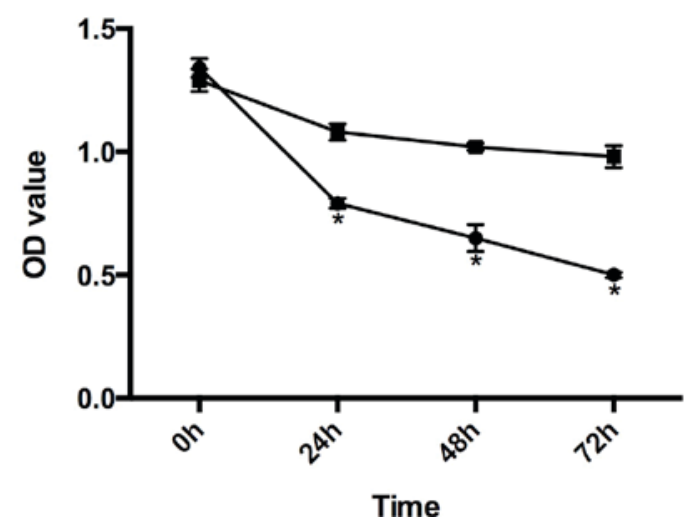

Figure 3. The relative survival rates at $0,24,48$ and $72 \mathrm{~h}$ in HCT116 cells following transfection, compared with the control group ("P<0.05). siRNA, small interfering RNA; TS, targeting siRNA; NS, nonspecific siRNA.

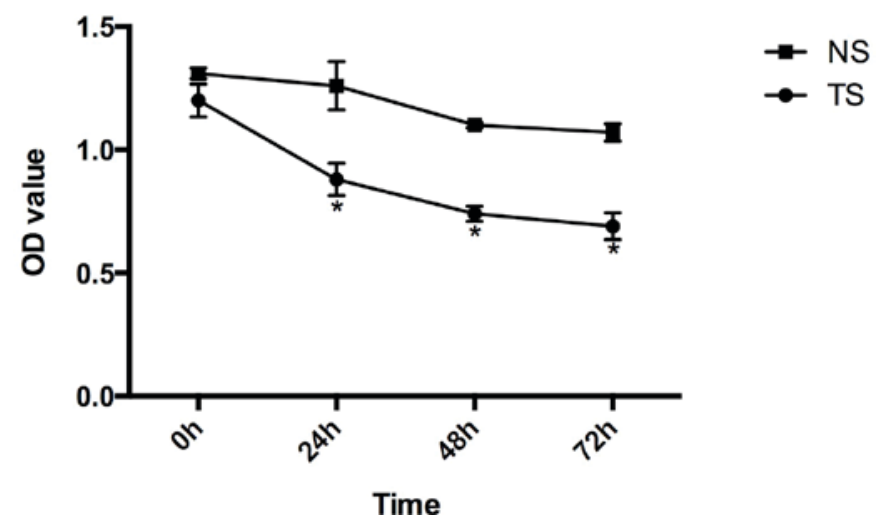

Figure 4. The relative survival rates at $0,24,48$ and $72 \mathrm{~h}$ in SW620 cells subsequent to transfection, compared with the control group (" $\mathrm{P}<0.05)$. siRNA, small interfering RNA; TS, targeting siRNA; NS, nonspecific siRNA.

Compared with the CG of SW620 cells, the relative survival rates of the TS group at $0,24,48$ and $72 \mathrm{~h}$ subsequent to transfection were $1.20 \pm 0.067,0.88 \pm 0.066,0.74 \pm 0.031$ and $0.69 \pm 0.054$, respectively, and in the NS group these were $1.31 \pm 0.022,1.26 \pm 0.098,1.10 \pm 0.011$ and $1.07 \pm 0.036$ (Fig. 4).

Cell apoptosis and cell cycle analysis by FCM. By FCM, the percentages of cells in the G1 and S phases in the TS group of HCT116 cells were 49.1 and $55.6 \%$, and in the CG these were 61.8 and $25.2 \%$, respectively. However, the percentages of cells in the G1 and S phases in the TS group of SW620 cells were 44.5 and $59.1 \%$, and in the CG these were 60.3 and $31.3 \%$, respectively.

These results showed that the proportion of cells transfected with siRNA targeting Beclin-1 in the G1 phase was significantly decreased $(\mathrm{P}<0.05)$, while the proportion of cells in the $\mathrm{S}$ phase was significantly increased $(\mathrm{P}<0.05)$. However, there were no evident changes in cell cycle distribution and proliferation in the NS group compared with the CG. The FCM results were consistent with the findings of CCK-8 (data not shown).

Proliferation analysis by MTT assay. The photo-absorption values in the HCT116 and SW620 cells in each group were measured. In the TS group of HCT116 cells, the values at 24, 48 and $72 \mathrm{~h}$ were $1.27 \pm 0.034,1.71 \pm 0.090$ and $1.95 \pm 0.066$,

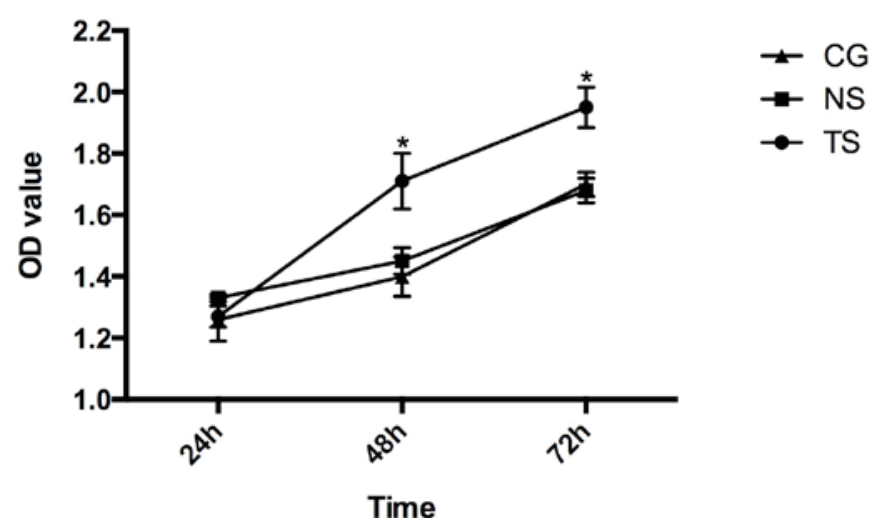

Figure 5. The photo-absorption values in the TS and NS groups, and CG of HCT116 cells, as measured by MTT assay. "P<0.05 vs. other groups at the same time point. siRNA, small interfering RNA; TS, targeting siRNA; NS, nonspecific siRNA; CG, control group.

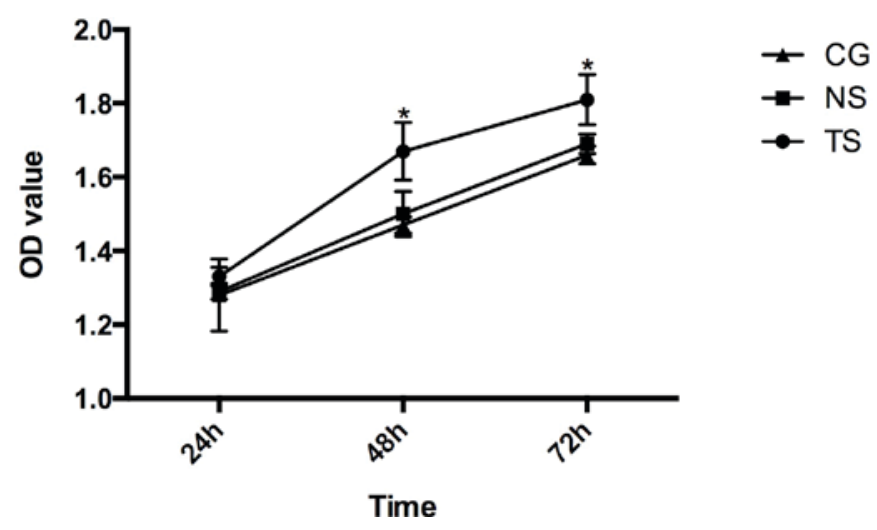

Figure 6. The photo-absorption values in TS, NS and CG groups of SW620 measured by MTT assay. "P $<0.05$ vs. other groups at the same time point. siRNA, small interfering RNA; TS, targeting siRNA; NS, nonspecific siRNA; CG, control group.

respectively. In the NS group, the values were $1.33 \pm 0.012$, $1.450 \pm 0.043$ and $1.68 \pm 0.040$. In the CG, the values were $1.26 \pm 0.071,1.40 \pm 0.064$ and $1.70 \pm 0.039$ (Fig. 5).

In the TS group of SW620 cells, the photo-absorption values at 24,48 and $72 \mathrm{~h}$ were $1.33 \pm 0.025,1.67 \pm 0.078$ and $1.81 \pm 0.068$, respectively. In the NS group, the values were $1.29 \pm 0.021,1.50 \pm 0.061$ and $1.69 \pm 0.026$. In the CG, the values were $1.28 \pm 0.098,1.47 \pm 0.022$ and $1.66 \pm 0.024$ (Fig. 6).

The results of the MTT assay showed that Beclin-1 silencing promoted cell proliferation compared with the CG $(\mathrm{P}<0.05)$, while there were no significant differences between the cell proliferation in the NS group and in the CG.

\section{Discussion}

CRC is one of the most common digestive tract cancers, with the second-highest cancer incidence in women and the third-highest cancer incidence in men worldwide. Every year, there are $\sim 1.2$ million patients with CRC and 600,000 of these succumb to CRC (8). At present, the CRC-associated incidence and mortality in China have been increasing (9). The main therapeutic strategies include surgical resection, radiotherapy and chemotherapy. However, the efficacy of treatment in the early stage of CRC is good, while it is poor in 
advanced CRC. Therefore, a new therapy for treating CRC is urgently required.

Autophagy, which has been indicated as a type of cell death different from apoptosis since the 1950s, has an important role in the generation and development of diseases. Autophagy is characterized by accumulation of autophagic vacuoles, without the formation of apoptosis bodies, and chromosome condensation, but the process is caspase-independent (10). In the generation and development of autophagy, parts of the cytoplasm or entire organelles are incorporated into autophagosomes, which are vesicles with a double membrane, and these finally fuse with lysosomes, change into a single-membrane structure and are degraded (11). Previous studies have demonstrated that autophagic capacity in cancer cells was decreased compared with normal cells, indicating that suppressing autophagy contributes to cancer development $(12,13)$.

At present, $>30$ associated genes, termed autophagy-related genes, are essential for autophagic induction, generation, maturation and recycling (14). Beclin-1 was hypothesized to be one of the critical molecules between apoptosis and autophagy (15). Beclin-1, $60 \mathrm{kDa}$, was functional in suppressing tumors by promoting cellular macroautophagy (16). Certain studies indicated that Beclin-1 improved the survival rate of cells, while other studies demonstrated that Beclin-1 acted as a tumor suppressor. Liang et al (17) found that the Beclin-1 expression decreased the proliferation of breast cancer MCF-7 cells. In lung and liver carcinomas, heterozygous disruption of Beclin-1 in mice increased the frequency of spontaneous lymphomas $(15,18)$. These results indicated that Beclin-1 had the ability to suppress tumor growth, which was associated with regulation of the death of autophagic cells. Yu et al (19) silenced Beclin-1 expression in L292 cells to prevent from autophagic death triggered by treatment with a caspase inhibitor. Shimizu et al (20) showed that the downregulation of Beclin-1 by RNAi blocked the death of non-apoptotic cells, which was induced by doubly knocking out B cell lymphoma-2 (Bcl-2) -associated X protein/Bcl-2 homologous antagonist/killer in mice.

In order to investigate the function of Beclin-1 in autophagy, cell proliferation and apoptosis, Beclin-1 expression was silenced in HCT116 and SW620 cells using RNAi. Using CCK-8, FCM and an MTT assay, the association between the downregulation of Beclin-1 expression and the proliferation and apoptosis of HCT116 and SW620 cells was investigated. The results showed that siRNA against Beclin-1 significantly decreased Beclin-1 expression, which led to the decrease of survival rate, as determined by CCK-8, and the increase of apoptosis rate and cell proliferation, as determined by FCM and MTT, respectively. The present results were consistent with the hypothesis that Beclin-1 may be an important molecule in adjusting autophagy and apoptosis in mammalian cells. However, the regulation mechanism of silencing Beclin-1 expression to promote cell apoptosis and autophagy remains unclear and requires additional investigation.

In the present study, it was found that compared to the NS group and CG, the decreased expression level of Beclin-1 in TS group effectively suppressed autophagy signaling, which affected the cell proliferation and cell cycle. As shown by FCM, the proportion of cells transfected with siRNA targeting
Beclin-1 in the G1 phase was significantly decreased $(\mathrm{P}<0.05)$, while the proportion of cells in the $\mathrm{S}$ phase was significantly increased $(\mathrm{P}<0.05)$, indicating the proliferation of cells in the TS group was promoted.

Beclin-1 was the first identified mammalian gene mediating autophagy (17). At present, numerous studies find that tumor suppressors, including Beclin-1, death-associated protein-kinase $(21,22)$ and phosphatase and tensin homolog (23), have a causative role in autophagy deficiencies in cancer formation. Therefore, autophagy draws more and more attention in studies about the tumor generating and developing (24,25). By inhibiting the expression of Beclin-1, the autophagy in CRC cells was not only suppressed, but the association between autophagy and cell proliferation and apoptosis was also indicated, which regulates tumor growth and has an effective anti-tumor effect. The present results provide new evidence for Beclin-1 as a target for regulating autophagy and treating CRC. The mechanism of how Beclin-1 is involved in autophagy and regulates cell proliferation and apoptosis require additional investigation.

\section{References}

1. Li Z and Zhu WG: Targeting histone deacetylases for cancer therapy: From molecular mechanisms to clinical implications. Int J Biol Sci 10: 757-770, 2014.

2. Ouyang L, Shi Z, Zhao S, Wang FT, Zhou TT, Liu B and Bao JK: Programmed cell death pathways in cancer: A review of apoptosis, autophagy and programmed necrosis. Cell Prolif 45: 487-498, 2012.

3. Hailey DW, Rambold AS, Satpute-Krishnan P, Mitra K, Sougrat R, Kim PK and Lippincott-Schwartz J: Mitochondria supply membranes for autophagosome biogenesis during starvation. Cell 141: 656-667, 2010.

4. Maiuri MC, Criollo A and Kroemer G: Crosstalk between apoptosis and autophagy within the Beclin 1 interactome. EMBO J 29: 515-516, 2010.

5. Yang Z and Klionsky DJ: Eaten alive: A history of macroautophagy. Nat Cell Biol 12: 814-822, 2010.

6. Kang R, Zeh HJ, Lotze MT and Tang D: The Beclin 1 network regulates autophagy and apoptosis. Cell Death Differ 18: 571-580, 2011.

7. Livak KJ and Schmittgen TD: Analysis of relative gene expression data using real-time quantitative PCR and the 2(-Delta Delta C(T)) Method. Methods 25: 402-408, 2001.

8. Jemal A, Center MM, DeSantis C and Ward EM: Global patterns of cancer incidence and mortality rates and trends. Cancer Epidemiol Biomarkers Prev 19: 1893-1907, 2010.

9. Ren JS, Chen WQ, Shin HR, Ferlay J, Saika K, Zhang SW and Bray F: A comparison of two methods to estimate the cancer incidence and mortality burden in China in 2005. Asian Pac J Cancer Prev 11: 1587-1594, 2010.

10. Levine B and Kroemer G: Autophagy in the pathogenesis of disease. Cell 132: 27-42, 2008.

11. Yoshimori T: Autophagy: A regulated bulk degradation process inside cells. Biochem Biophys Res Commun 313: 453-458, 2004.

12. Gozuacik D and Kimchi A: Autophagy as a cell death and tumor suppressor mechanism. Oncogene 23: 2891-2906, 2004.

13. Thompson C B: Apoptosis in the pathogenesis and treatment of disease. Science 267: 1456-1462, 1995.

14. Behrends C, Sowa ME, Gygi SP and Harper JW: Network organization of the human autophagy system. Nature 466: 68-76, 2010.

15. Yue Z, Jin S, Yang C, Levine AJ and Heintz N: Beclin 1, an autophagy gene essential for early embryonic development, is a haploinsufficient tumor suppressor. Proc Natl Acad Sci USA 100: 15077-15082, 2003.

16. Zeng X, Overmeyer JH and Maltese WA: Functional specificity of the mammalian Beclin-Vps34 PI 3-kinase complex in macroautophagy versus endocytosis and lysosomal enzyme trafficking. J Cell Sci 119: 259-270, 2006. 
17. Liang XH, Jackson S, Seaman M, Brown K, Kempkes B, Hibshoosh $\mathrm{H}$ and Levine B: Induction of autophagy and inhibition of tumorigenesis by beclin 1. Nature 402: 672-676, 1999.

18. Qu X, Yu J, Bhagat G, Furuya N, Hibshoosh H, Troxel A, Rosen J, Eskelinen EL, Mizushima N, Ohsumi Y, et al: Promotion of tumorigenesis by heterozygous disruption of the beclin 1 autophagy gene. J Clin Invest 112: 1809-1820, 2003.

19. Yu L, Alva A, Su H, Dutt P, Freundt E, Welsh S, Baehrecke EH and Lenardo MJ: Regulation of an ATG7-beclin 1 program of autophagic cell death by caspase-8. Science 304: 1500-1502, 2004.

20. Shimizu S, Kanaseki T, Mizushima N, Mizuta T, ArakawaKobayashi S, Thompson CB and Tsujimoto Y: Role of Bcl-2 family proteins in a non-apoptotic programmed cell death dependent on autophagy genes. Nat Cell Biol 6: 1221-1228, 2004.

21. Zalckvar E, Berissi H, Mizrachy L, Idelchuk Y, Koren I, Eisenstein M, Sabanay H, Pinkas-Kramarski R and Kimchi A: DAP-kinase-mediated phosphorylation on the $\mathrm{BH} 3$ domain of beclin 1 promotes dissociation of beclin 1 from Bcl-XL and induction of autophagy. EMBO Rep 10: 285-292, 2009.
22. Zalckvar E, Berissi H, Eisenstein $M$ and Kimchi A: Phosphorylation of Beclin 1 by DAP-kinase promotes autophagy by weakening its interactions with Bcl-2 and Bcl-XL. Autophagy 5: 720-722, 2009.

23. Ying $\mathrm{H}, \mathrm{Qu} \mathrm{D}$, Liu $\mathrm{C}$, Ying $\mathrm{T}, \mathrm{Lv} J$, Jin $\mathrm{S}$ and $\mathrm{Xu} \mathrm{H}$ : Chemoresistance is associated with Beclin-1 and PTEN expression in epithelial ovarian cancers. Oncol Lett 9: 1759-1763, 2015.

24. Won KY, Kim GY, Lim SJ, Sung JY, Kim YW, Park YK, Lee J and Choi HS: Autophagy is related to the hedgehog signaling pathway in human gastric adenocarcinoma: Prognostic significance of Beclin-1 and Gli2 expression in human gastric adenocarcinoma. Pathol Res Pract 211: 308-315, 2015.

25. Galadari S, Rahman A, Pallichankandy S and Thayyullathil F: Tumor suppressive functions of ceramide: Evidence and mechanisms. Apoptosis 20: 689-711, 2015. 